\title{
Takma Uçlu Matkap Ve Kesme Parametrelerinin Seçimi İçin Bir Uzman Sistem
}

\author{
Yunus Kayır ${ }^{\text {a }}$, Ercan Demirer ${ }^{a}$, Serkan Güneş ${ }^{b}$ \\ ${ }^{a}$ Gazi Üniversitesi İmalat Mühendisliği Bölümü, 06500, Teknikokullar, Ankara, Türkiye \\ bazi Üniversitesi Makine Mühendisliği Bölümü, 06570, Maltepe, Ankara, Türkiye \\ ykayir@gazi.edu.tr, serkan.gunes@gazi.edu.tr
}

Received/Geliş: 16.05.2018 Revised/Düzeltme: $27.06 .2018 \quad$ Accepted/Kabul: 04.07.2018

Özet: Takma uçlu matkaplar, delik delme operasyonlarında yaygın kullanılan kesici takımlardır. Piyasada, çok farklı tip ve özellikte olan takma uçlu matkaplar bulunmaktadır. Arzu edilen delik kalitesinin elde edilmesinde, uygun bir takma uçlu matkabın ve doğru kesme parametrelerin belirlenmesi gerekmektedir. Bu hazırlıklar için bir uzmana ihtiyaç duyulmaktadır. Bundan dolayı, en uygun kesici takımı ve kesme parametrelerini otomatik belirleyen, Expert for Insert Drilling Tool (EIDT) olarak adlandırılan, bir uzman sistem geliştirilmiştir. EIDT'nin geliştirilmesinde KAPPA-PC uzman sistem paket programı kullanılmıştır. Sistemin tasarımında 150'den fazla kural oluşturulmuştur. Kurallar, ISO normlarına göre hazırlanmıştır. EIDT programı delik çapı ve boyu, tolerans aralıkları, işlenecek malzeme özellikleri, delik türü ve operasyon tipi, vb. gibi veriler kullanılarak en uygun kesici takım önermektedir. Yapılan bu çalışma ile delik delme operasyonlarında uzman olmayan bir kişinin takma uçlu matkapları ve kesme parametrelerini, kolay, hızlı ve doğru bir şekilde seçebilmesi sağlanmıştır.

Anahtar kelimeler: Ucu değişebilir matkap, delik delme, takma uçlu matkap, uzman sistem, KAPPA-PC.

\section{An Expert System For Selection Insert Drilling Tools And Cutting Parameters}

\begin{abstract}
The insert Drilling tools are widely used in drilling processes. There are many indexable drilling tools in markets over the world. The types and specifications of them are very different each other. The selection of a suitable insert drilling tools and correct cutting parameters is needed to get the desired hole quality. An expert person must be worked for that tasks. Hence, an expert system that is called Expert for Insert Drilling Tool (EIDT) was developed. KAPPA-PC shell program was used to implement the EIDT. More than 150 rules were used to design the expert system. The rules were written for ISO norms standardized the indexable drills. The EIDT suggests an optimum solution for specifications of holes (diameter, depth, tolerance, etc.) and workpiece materials (type, hardness, etc.) entered into the system. Thus, the system provides someone who is not expert to select insert drilling tools easily and quickly, and correctly in drilling processes.
\end{abstract}

Keywords: Indexable drill, drilling, insert drilling tool, expert system, KAPPA-PC

\section{Giriş}

Delik delme, talaşlı imalatta en yaygın kullanılan yöntemlerden biridir [1,2]. Delik delme işlemlerinde kullanılan çok fazla kesici takım seçeneği bulunmaktadır. Uygun olmayan kesici ve kesme parametreleri, delik delme işlemini ve elde edilecek olan delik kalitesini doğrudan etkilemektedir. Delinen delikler üzerinde yapılacak olan ilave işlemler ve uzayan süreç talaşlı imalat maliyetlerini artırmaktadır. Yapay Zekâ tekniklerden biri olan uzman sistemler, günümüzde 
hemen hemen her alanda kendine yer bulabilmektedir [3,4]. Talaşlı imalat, uzman sistemler için uygulanabilirliği çok yüksek bir alandır. Uzman birisinin olmadığı durumlarda delik delme operasyonlarına yönelik kesici takım ve kesme parametrelerinin seçiminde uzman sistemlerinden faydalanılması oldukça önemlidir. Geliştirilen uzman sistemler, alanında uzman olmayan veya tecrübesiz bir operatörün kendi başına karar verme inisiyatifini ortadan kaldırmaktadır. Bununla birlikte, uzman sistemler, uzman birisinin gözünden kaçabilecek olası durumlarda hatalı kararların verilebilmesinin de önüne geçmektedir. Böylelikle de elde edilmek istenilen sonuçlara ulaşılmasında tesadüflere ve hatalara yer bırakılmamaktadır [5,6]. Uzman sistemler genel olarak konunun uzmanı tarafından yapılan görevleri, tek başına yerine getiren bilgisayar programlarıdır. Uzman sistem programları, problem çözümünde uzmanlık bilgisini ve gerekli tecrübeyi bir araya getirerek görev yaparlar [6]. Bilgi tabanlı bir karar destek sistemi olarak çalışırlar [7]. Uzman sistemler, genel olarak veri işlemeden, bilgi işlemeye bir geçiş olarak tanımlanabilir. Normal programlarda olduğu gibi veri tabanı bir algoritmaya bağlı bir şekilde işlenirken, uzman sistemlerde bilgi, herhangi bir algoritmaya bağlı olunmaksızın çıkarılmış kurallar ve gerçeklerden oluşturulan bilgi tabanı işlenmektedir [8]. Uzman sistemler, yapay zeka bölümünde bulunun alt dallardan biridir. Temelde uzman sistemler, insanın bilgi ve tecrübesini kullanmaya çalışan bilgisayar programlarıdır [9]. Bir bilgi tabanlı sistemdir. Bir kral tabanlı bilgisayar yazılımıdır. En genel olarak uzman sistemler; ele alınan bir uygulama alanındaki karışık problemleri çözmek amacı ile bir uzmanın düşünme işlemlerine ve aşamalarına benzer tarzda çalışıp hareket eden yazılım ve donanımlardan oluşan bilgisayar sistemleridir [7-9]. Günümüze kadar uzman sistemler ile ilgili birçok akademik çalışma yapılmıştır.

Muthsam bir çalışmasında, prizmatik parçalara yönelik işlem planlaması CAPP (Computer Aided Process Planning) için bir uzman sistem geliştirmiştir. Frezeleme ve delik delme işlemleri için kesici seçimini gerçekleştiren bir system tasarlamışlardır [10]. Eskicioğlu, bir işlem planlama sistemi CAPP için bir uzman sistemi geliştirmiştir. Uzman CAPP sistemi, yüzey frezeleme, çevresel frezeleme, delik delme, delik büyütme ve havşa açma gibi temel işlemler için planlamaları otomatik olarak hazırlamaktadır [11]. Arezoo; kesici takımların ve kesme şartlarının belirlenmesi için, bilgi tabanlı bir uzman sistem geliştirmişlerdir. Uzman sistemin geliştirilmesinde Prolog programlama dili kullanmışlardır [12]. Tan, CNC torna tezgâhları için karbür takım seçimi yapan bir uzman sistem hazırlamışlardır [13]. Geliştirilen sistemde, kullanıcının sorulara (devir, ilerleme, malzeme, operasyon tipi, vb.) verdiği cevaplar doğrultusunda kesici takıma karar verilmektedir. Tan diğer bir çalışmasında ise, iş parçasına uygulanacak olan tornalama operasyonları için en uygun tezgah seçimi yapan bir uzman sistem tasarlamıştır. Uzman sistemin geliştirilmesinde Kappa-PC programını tercih etmiştir [14]. Ugras, delik büyültme operasyonlarında yaygın olarak kullanılan baralama takımlarının ve kesici uçlarının seçimine yönelik bir uzman sistem geliştirmiştir [15]. Kappa-PC paket programı ile geliştirilen sistem, işlenecek olan delik ölçüleri ve malzeme için en uygun baralama takımı ve kesici uçlarını kullanıcıya önermektedir. Başak, Leonardo uzman sistem paket programı kullanarak yapmış olduğu çalışmasında vida çekme operasyonları için kılavuz tipi belirleyen bir uzman sistem geliştirmiştir. Geliştirilen program; vida çekilecek malzemeye, talaş tipine, kesme hızına, çalışma şartlarına vb. göre kullanıcıyı yönlendirerek en uygun kılavuz tipini belirleyebilmektedir [16]. Telek, Kappa-PC uzman sistem yazılımını kullanarak en uygun Alüminyum alaşımını belirleyen bir uzman sistem geliştirmiştir. Geliştirilen uzman program, kullanılacak olan, mekanik özellikleri, işlenebilirlik, çevre şartları, vb. bilgileri kullanıcıdan almaktadır. Girilen veriler doğrultusunda en uygun Alüminyum alaşımı sistem tarafından önerilmektedir [17]. Benzer bir çalışmayı, Zarandi ve arkadaşları yapmışlardır [18]. Çalışmalarında, sürdürülebilir üretim için en uygun malzeme seçimini yapan bir uzman sistemi Kappa-PC paket programı kullanarak geliştirmişlerdir. Sistem, bir metal konstrüksiyon işinde kullanıcının girdiği bilgilere göre (yük, boy, vb.), en uygun malzemeye karar vermektedir. Diğer yandan, Usta ve arkadaşlarının yaptığı bir çalışmada, Kappa-PC yazılımını kullanarak on ayrı işin aynı anda yapılması durumunda, imalat hücresine karar veren, tezgah işlem sıralamalarını ve hücredeki robotun bu işleri tezgahlara hangi zamanlarda ve hangi sıra ile yerleştirip-alması gerektiğini 
belirleyen bir uzman sistem geliştirilmiştir [19]. Benzer bir çalışmayı Tan ve arkadaşları yapmışlardır [20]. Geliştirdikleri sistem, bir imalat alanına yönelik olarak robot seçimi yapmaktadır. Sistemin tasarlanmasında, Kappa-PC paket programını kullanmışlardır.

Görüldügü üzere, dünya üzerinde talaşlı imalat konusunda birçok uzman sistem geliştirilmiş ve geliştirilmeye de devam edilecektir. İncelemelerde, takma uçlu matkaplar için yapılmış bir çalışma ile karşılaşılmamıştır. Dolayısı ile delik delme işlemlerinde yaygın kullanıma sahip takma uçlu matkaplara yönelik bir uzman sistemin geliştirilmesine gidilmiştir. Geliştirilen sistem, kullanıcıdan aldığ kesme parametrelerini önermektedir.

\section{Geliştirilen Sistem}

Talaşlı imalat işlemlerinde delik delme, en sık başvurulan bir yöntemdir [21]. Günümüzde delik delme operasyonları için çok farklı tip ve özelliklere sahip kesici takımlar kullanılmaktadır. En yaygın kullanılanları normal helisel yekpare matkaplar (solid twist drill) ve takma uçlu matkaplardır (indexable, insert drill). Takma uçlu matkaplar, delik delme süresinin ve operasyon sayısının azaltılması, delik toleranslarının (boyut, şekil konum, yüzey) tutturulması, vb. avantajlarından dolayı öne çıkan kesici takımlardır. Helisel yekpare matkaplara kıyasla, takma uçlu matkaplar ile yapılan bir delik delme işlemi, son (finish) işleme operasyonu olarak yapılmaktadır [22]. Bununla birlikte, normal helisel matkapların kesici ağızları matkap gövdesi ile bir bütün olurken, takma uçlu matkaplarda ise kesici ağızlar ise çıkarılabilir, değişebilir olacak şekilde gövdeye bağlanmaktır (Şekil 1'de bir takma uçlu matkap ve uçları verilmiştir). Takma uçlu matkaplar, ucun sayısı ve montaj konumu, şekli, tipi, vb. birçok faktöre bağlı olarak değişik boyutlarda üretilmektedir. Takma uçlu matkapların, temelde delinecek olan delik boyutları, delik toleransı, delinecek olan malzeme özellikleri olmak üzere daha birçok faktöre göre doğru seçilmesi elde edilecek delik ve gerçekleştirilecek olan operasyon için çok önemlidir [23,24].

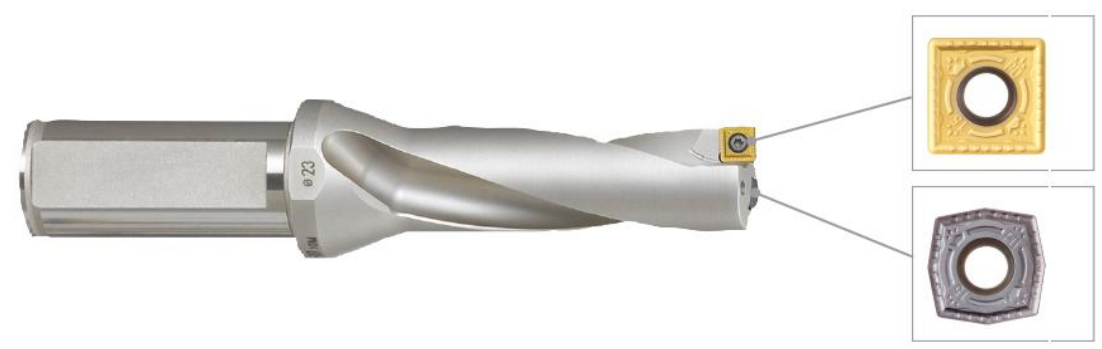

Şekil 1. Bir takma uçlu matkap [25]

$\mathrm{Bu}$ çalışmada, takma uçlu matkapların bir uzmana gereksinim duyulmadan seçimini yapan bir uzman sistemin geliştirilmesine gidilmiştir. EIDT ismi verilen sistem, Kappa-PC uzman sistem paket programı kullanılarak tasarlanmıştır. Kappa-PC, bilgi ve kural tabanlı olan bir paket programıdır [26]. Windows altında çalışan Kappa-PC, kullanılan diğer uzman sistem yazılımlarından farklı olarak kuralların yanı sıra diğer sistem elemanlara da sahiptir. Kappa-PC içerisinde sistem bileşenleri hiyerarşik bir düzen içinde "sınıf" (class) veya "öge" (instance) adı verilen nesnelerle tanıtılır. Hiyerarşik yapı içinde, yukarı kademelerde bulunan sınıflar için tanımlanan özellikler ve bilgiler aynı sınıfın aşağı kademelerdeki sınıflarına ve ögelerine intikal eder. Sınıf ve öge şeklinde tanıtılmış uzman sistem elemanlarının ne yapmalarının gerektiği uzman sisteme metotlar olarak öğretilir. KAPPA-PC, metotlar içinde yer alabilecek, "EXE" haline dönüştürülmüş bütün programları kendi içinde çalıştırma yeteneğine de sahiptir [26]. Kappa-PC uygulamasında sistemin genel yapısı Object Browser adı verilen ortamda ağacın dalları şeklinde görüntülenir. Bu çalışmada oluşturulan uzman sistemin genel yapısı Şekil 1'de verilen matkaplar nesnesi ile tanımlanmıştır. Şekil 1'de, soldan sağa doğru olan akış takip edildiğinde bir önceki 
nesneden alınan veriler bir sonraki nesneye aktarılmaktadır ve en son nesne kendinden önce gelen tüm nesnelerin özelliklerini barındırmaktadır. Şartların gerektirmesi durumunda ilave özellikleri içermesi de mümkündür.

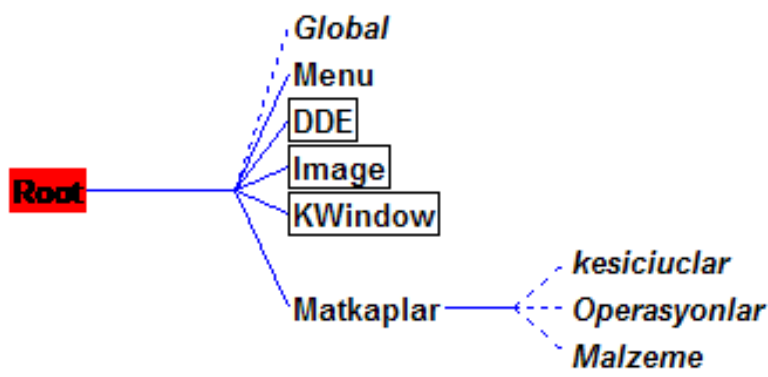

Şekil 2. Kappa-PC programı ağaç yapısında, geliştirilen uzman sistem için tanımlanan nesneler

Geliştirilen EIDT programı, Matkaplar sınıfı ile başlamaktadır. Matkaplar sınıfı için, piyasada delik delme uygulamalarında sıklıkla kullanılan UDRILL, TPDB, WPDC, vb. takma uçlu matkaplara yönelik bilgi yapıları (slots) oluşturulmuştur. Takma uçlu matkap bilgileri, piyasada yaygın kullanıma sahip bir kesici takım kataloğundan alınmıştır [25]. Geliştirilen sistemde bir çeşit kesici takım kütüphanesi gibi görev yapmaktadır. Matkaplar sınıfı içerisinde Kesici Uçlar, Operasyonlar ve Malzeme olmak üzere 3 ayrı modül bulunmaktadır. Kesici Uçlar modülü içerisinde takma uçlu matkaplarda kullanılan uç tipleri ve kaplama çeşitleri yer almaktadır. İkinci modül Operasyonlar modülüdür. Operasyonlar modülü ile delme operasyonunun tipi belirlenmektedir. Bu modül altında iki bölüm yer almaktadır. Birinci bölümde delik tipi (boyadan boya delik, kör delik, vb.), diğer bölümde ise deliğin parça üzerindeki konumu (kenarda, açılı yüzeyde, vb.) seçilmektedir. Son modül olan Malzeme de ise delinecek olan malzeme tipi belirlenmektedir. Malzeme seçimi, önemli kriterlerden biridir ve önerilecek takma uçlu takım üzerinde doğrudan belirleyici özelliğe sahiptir. Genel olarak iş parçası malzemeleri, P, M, S, K, N olmak üzere 5 sınıfa (kullanılan kesici katoloğunda en yaygın takma uçlu matkaplar bu malzemeler için önerilmiştir) ayrılmıştır. Her sınıf içerisinde malzemenin farklı türleri verilmiştir. Tüm modüllere yönelik olarak 150 den fazla kural (Rules) oluşturulmuş ve bunlara yönelik olarak ta birçok bilgi ataması (slots) yapılmıştır. Bilindiği gibi uzman sistemlerde, kuralların en uygun sonuçların elde edilmek üzere değerlendirilmesinde temel iki yöntem: ileri zincirleme (forward chaining) ve geri zincirleme (Backward chaining) kullanılmaktadır [26]. EIDT programında, kural tabanındaki kuralların değerlendirilmesinde geriye zincirleme (forward chaining) yöntemi tercih edilmiştir.

\section{Uzman Sistem İle Takma Uçlu Matkapların Seçimi}

EIDT Programı çalıştırıldığında Şekil 3.'deki gibi bir sayfa açılır (Anasayfa). Açılan sayfa, EIDT programının ilk sayfası olup, diğer sayfalara geçişler bu sayfa üzerinde sağlanmıştır. Anasayfa üzerinde, kullanıcı girişi ve seçimi için ayrılmış yerler bulunmaktadır. Bilgi girişi, sayfa üzerindeki delik çapı ve delik boyu değerlerinin girilmesi ile başlamaktadır. Bu değerlerin girilmesi delme takımı önerisini doğrudan etkilediğinden dolayı çok önemlidir. Geliştirilen sistemde, UDRILL kesici için en büyük delik çapı $60 \mathrm{~mm}$ ve en fazla delik boyu ise $300 \mathrm{~mm}$ olarak belirlenmiştir. Bir sonraki adımda delik tolerans değeri seçilecektir. Genelde, kesici kataloglarında takma uçlu matkaplar, elde edilecek delik tolerans bilgilerine göre gruplandırılmıştır. Dolayısı ile takma uçlu takımlar için belirlenmiş olan tolerans değerleri burada kullanılmıştır. Sistemde, H10, H11, H12, ISO 27668f, ISO 27668m, ISO 27668c, ISO 27668v toleranslar tanımlanmıştır. Kullanıcı arzu ettiği delik toleransını kendisine sunulan liste içinden seçebilmektedir. Ĕger isterse bu tolerans için bilgiyi, sayfa üzerinde oluşturulmuş düğme (Tolerans Cetveli) ile açılan tolerans sayfasından görebilmektedir (Şekil 4). Seçilen toleransın ardından, üst ve alt tolerans değerleri otomatik olarak sayfa üzerinde görüntülenmektedir. 


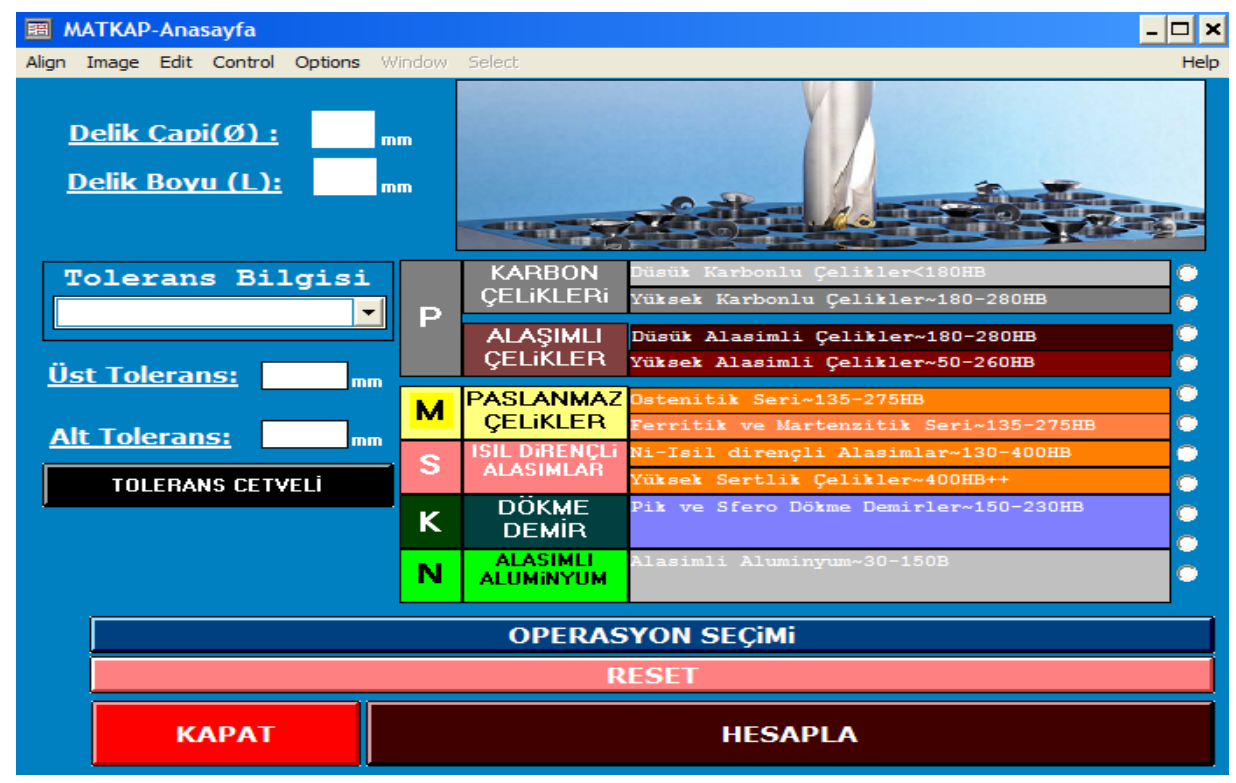

Şekil 3. EIDT programının ana sayfa

\begin{tabular}{|c|c|c|c|c|c|c|c|c|c|c|c|c|c|c|c|c|}
\hline \multicolumn{16}{|c|}{ ERTOLERMS } & \multirow{2}{*}{$\frac{- \text { 미 } x}{\text { Heb }}$} \\
\hline Non in & e Ed & it con & & Ootions & Wride & or 5 & $\sqrt{6 e d}$ & & & & & & & & & \\
\hline \multicolumn{2}{|c|}{$\begin{array}{c}\text { ANMA } \\
\text { OLCOSO } \\
\text { REAL. } \\
\text { DLAMETER } \\
\text { (mm) } \\
\text { (mming }\end{array}$} & \multicolumn{5}{|c|}{$\begin{array}{l}\text { DELIK TOLERANSLARI } \\
\text { HOLL. TOL.ERANCE }\end{array}$} & \multicolumn{9}{|c|}{$\begin{array}{l}\text { MII. TOLERANSI.ARI } \\
\text { ROD TOLERANCE }\end{array}$} & \\
\hline$>$ & $<$ & 118 & 119 & 1110 & H11 & H12 & e9 & n & 7 & $\mathrm{~B}$ & $\theta$ & h8 & h9 & A10 & h11 & \\
\hline 0 & 3 & $\begin{array}{c}+14 \\
-0\end{array}$ & $\begin{array}{r}+25 \\
-0\end{array}$ & $5 \mid \begin{array}{c}+40 \\
-0\end{array}$ & $\begin{array}{c}+60 \\
-0\end{array}$ & $\begin{array}{c}+100 \\
-0\end{array}$ & $\begin{array}{l}-14 \\
-39\end{array}$ & $\begin{array}{l}- \\
-1 \\
-1\end{array}$ & \begin{tabular}{c|c}
6 & - \\
16 &.
\end{tabular} & $\begin{array}{c}-6 \\
-20\end{array}$ & $\begin{array}{c}-6 \\
-31\end{array}$ & $\begin{array}{l}-0 \\
-14\end{array}$ & $\mid \begin{array}{c}-0 \\
-25\end{array}$ & $\begin{array}{l}-0 \\
-40\end{array}$ & $\begin{array}{l}-0 \\
-60\end{array}$ & \\
\hline 3 & 6 & $\begin{array}{l}-0 \\
+18 \\
-0\end{array}$ & $\begin{array}{l}.00 \\
+30 \\
.0\end{array}$ & $0 \begin{array}{c}-0 \\
+48 \\
-0\end{array}$ & $\begin{array}{c}-0 \\
+75 \\
-0\end{array}$ & $\begin{array}{c}-0 \\
+120 \\
-0\end{array}$ & $\begin{array}{l}-39 \\
0.20 \\
.50\end{array}$ & $\mid \begin{array}{l}-1 \\
-1 \\
-2\end{array}$ & $\begin{array}{lll}10 & -5 \\
10 & - & -\end{array}$ & $\begin{array}{l}-20 \\
-10 \\
-28\end{array}$ & \begin{tabular}{|l|}
-31 \\
-10 \\
-40
\end{tabular} & $\begin{array}{l}-17 \\
-0 \\
.18\end{array}$ & $\begin{array}{l}-20 \\
-0 \\
-30\end{array}$ & $\begin{array}{l}-40 \\
-0 \\
-48\end{array}$ & $\begin{array}{c}-80 \\
-0 \\
-75\end{array}$ & \\
\hline 6 & 10 & $\begin{array}{l}+22 \\
-0 \\
\end{array}$ & $\begin{array}{l}+36 \\
-0 \\
\end{array}$ & \begin{tabular}{c|c}
+58 \\
-0
\end{tabular} & $\begin{array}{c}+90 \\
-0\end{array}$ & $\begin{array}{l}+150 \\
-0\end{array}$ & $\begin{array}{l}0.25 \\
-61\end{array}$ & $\begin{array}{l}-1 \\
-2\end{array}$ & $13:$ & $\begin{array}{r}-13 \\
-35\end{array}$ & $\begin{array}{l}-13 \\
-49 \\
\end{array}$ & $\begin{array}{r}-0 \\
-22 \\
\end{array}$ & $\begin{array}{l}-30 \\
-0 \\
-36\end{array}$ & $\begin{array}{l}-0 \\
-58\end{array}$ & $\begin{array}{c}-0 \\
-90 \\
-90\end{array}$ & \\
\hline 10 & 18 & $\begin{array}{l}+27 \\
-0\end{array}$ & $\begin{array}{r}+43 \\
.0\end{array}$ & $\begin{array}{c}+70 \\
-0\end{array}$ & $\begin{array}{l}+110 \\
-0\end{array}$ & $\begin{array}{c}+180 \\
.0\end{array}$ & $\begin{array}{l}0.32 \\
.75\end{array}$ & & \begin{tabular}{l|l}
16 & $:$ \\
34 & $:$
\end{tabular} & $\begin{array}{l}-16 \\
-43\end{array}$ & $\begin{array}{l}-16 \\
-59\end{array}$ & $\begin{array}{l}-0 \\
.27\end{array}$ & $\begin{array}{l}-0 \\
-43\end{array}$ & $\begin{array}{l}-0 \\
-70\end{array}$ & $\begin{array}{c}-0 \\
-110\end{array}$ & \\
\hline 18 & 30 & \begin{tabular}{|c|}
+33 \\
-0 \\
\end{tabular} & $\begin{array}{l}+52 \\
-0\end{array}$ & $2 \begin{array}{c}+84 \\
-0\end{array}$ & $\begin{array}{c}+130 \\
-0\end{array}$ & $\begin{array}{c}+210 \\
-0\end{array}$ & $\begin{array}{l}0-40 \\
-92\end{array}$ & -2 & $\begin{array}{l}20 \\
41\end{array}$ & $\begin{array}{r}-20 \\
-53\end{array}$ & $\begin{array}{l}-20 \\
-72\end{array}$ & $\begin{array}{l}-0 \\
-33\end{array}$ & \begin{tabular}{|l|l} 
& -0 \\
-5 & -52
\end{tabular} & $\begin{array}{l}-0 \\
-84 \\
-84\end{array}$ & $\begin{array}{c}-0 \\
-130\end{array}$ & \\
\hline 30 & $s_{0}$ & $\begin{array}{c}+39 \\
-0\end{array}$ & $\begin{array}{r}+62 \\
.0\end{array}$ & $2+100$ & $\begin{array}{c}+160 \\
-0\end{array} \mid$ & $\begin{array}{r}+250 \\
-0\end{array}$ & $\begin{array}{l}0.50 \\
-112\end{array}$ & $\begin{array}{l}-2 \\
-5\end{array}$ & $\begin{array}{lll}25 & . \\
50 & & \end{array}$ & $\begin{array}{r}-25 \\
-64\end{array}$ & $\begin{array}{l}-25 \\
-87\end{array}$ & $\begin{array}{r}.0 \\
.39\end{array}$ & $\begin{array}{l}-0 \\
-62\end{array}$ & $\begin{array}{c}-0 \\
-100\end{array}$ & $\begin{array}{l}-0 \\
.160\end{array}$ & KAPAT \\
\hline so & 80 & $\begin{array}{c}+46 \\
-0 \\
\end{array}$ & $\begin{array}{r}+74 \\
.0 \\
\end{array}$ & $\begin{array}{c}+120 \\
-0\end{array}$ & $\begin{array}{c}+190 \\
-0 \\
\end{array}$ & $\begin{array}{r}+300 \\
-0 \\
\end{array}$ & $\begin{array}{l}0.60 \\
-134 \\
\end{array}$ & $\begin{array}{l}-3 \\
-6\end{array}$ & \begin{tabular}{l|l}
30 & - \\
60 & -
\end{tabular} & $\begin{array}{r}-30 \\
-76 \\
\end{array}$ & \begin{tabular}{|l|}
-30 \\
-104 \\
\end{tabular} & $\begin{array}{l}-0 \\
-46 \\
\end{array}$ & \begin{tabular}{|c|c} 
& -0 \\
6 & -74 \\
\end{tabular} & $\begin{array}{c}-0 \\
-120 \\
\end{array}$ & $\begin{array}{c}-0 \\
-190 \\
\end{array}$ & \\
\hline \multicolumn{16}{|c|}{ DIN ISO 2768-2 } & \\
\hline \multirow{2}{*}{\multicolumn{2}{|c|}{\begin{tabular}{|l} 
Tolerance- \\
class
\end{tabular}}} & \multicolumn{13}{|c|}{ Uimits in $\mathrm{mm}$ for nominal sites in mm } & & \\
\hline & & $\begin{array}{c}0.5 \mathrm{t} \\
3\end{array}$ & & $\begin{array}{l}\text { Abeve } \\
3 \text { to } 6\end{array}$ & $\begin{array}{l}\text { Above } \\
\text { to } 30\end{array}$ & & $\begin{array}{l}\text { bove } 30 \\
\text { to } 120\end{array}$ & & $\begin{array}{l}\text { Abo } \\
120 \\
40\end{array}$ & to & $\begin{array}{l}\text { Abor } \\
400 \\
100\end{array}$ & & $\begin{array}{c}\text { Above } \\
1000 \\
\text { to } \\
2000\end{array}$ & $\begin{array}{l}\text { Abov } \\
2000 \\
400 \mathrm{~K}\end{array}$ & & \\
\hline \multicolumn{2}{|c|}{ fline) } & \pm 0.0 & & +0.05 & \pm 0.01 & & \pm 0.15 & & +0 & & \pm 0 & & \pm 0.5 &. & & \\
\hline \multicolumn{2}{|c|}{ m (medium) } & \pm 0.1 & & \pm 0.1 & $\pm 0,2$ & & \pm 0.3 & & \pm 0 & & \pm 0 & & \pm 1.2 & \pm 2 & & \\
\hline \multicolumn{2}{|c|}{ C (coarse) } & 20,1 & & \pm 0.2 & 20,5 & & 208 & & 21 & & \pm 2 & & \pm 3 & \pm 4 & & \\
\hline \multicolumn{2}{|c|}{$\begin{array}{l}\text { vivery } \\
\text { coarse) }\end{array}$} & 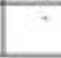 & & 20,5 & 21 & & 21,5 & & 22 & & 24 & & 26 & \pm 8 & & \\
\hline
\end{tabular}

Şekil 4. Tolerans cetveli

Ana sayfada yapılacak son seçim iş parçası malzemesinin seçimidir. EIDT programında kullanımı en yaygın malzemeler, P, M, S, K, N olarak 5 malzeme sınıf altında toplanmıştır (Şekil 5). Kullanıcı delik deleceği parçanın malzemesini, verilen sınıflardan birisi olarak seçmek durumundadır. Her malzeme grubu içerisinde kullanıcıyı bilgilendirmek amacı ile sertlik değerleri de verilmiştir. Malzemenin doğru seçilmesi çok kritik bir aşamadır. Çünkü malzeme seçiminde yapılacak yanlış; takma uçların ve kesme parametrelerin doğru belirlenmesini etkileyecektir. Bu durumda, iş parçasında bozulmalara, takım kırılmalarına, vb. sorunların çıkmasına neden olabilmektedir. 


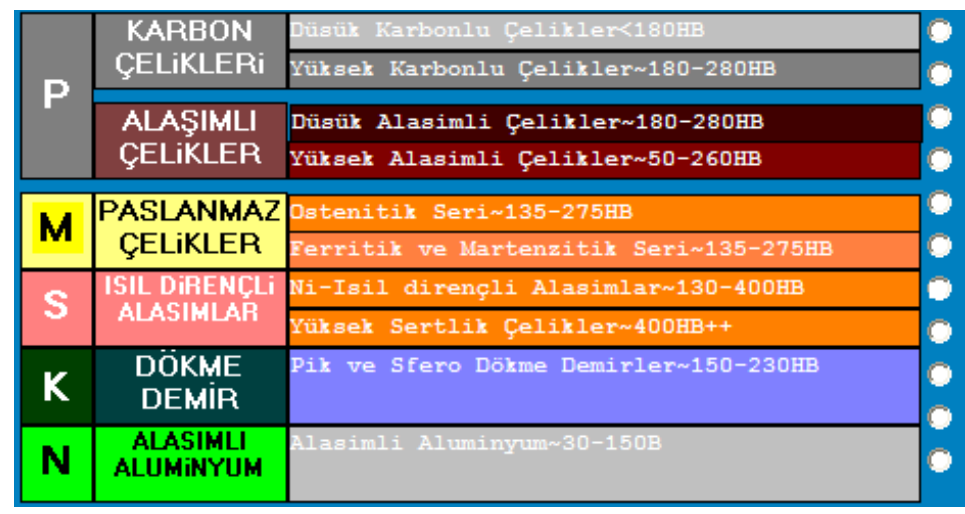

Şekil 5. İş parçası malzemeleri

Ana sayfada tüm seçimler ve girişler yapıldıktan sonra bir sonraki sayfaya geçiş yapılır. Bir sonraki aşama, delinecek olan delik ve operasyon tipinin seçilmesidir. Bunu için, program Anasayfa (Şekil 3) üzerinde bulunan Operasyon Seçimi butonuna tıklandığında kullanıcıya yeni bir sayfa sunulmaktadır (Şekil 6). Açılan sayfa (Operasyon Seçimi) üzerinde kullanıcı, kendisine uygun olan delik tipi ve operasyon tipini seçmesi gerekmektedir. Seçimin ardından sayfa üzerinde bulunan Anasayfa düğmesi ile işlem sonlanarak sayfa kapatılır. Ekranda tekrar ilk program sayfası olan Anasayfa görülür. Böylelikle de program için gerekli olan tüm giriş ve seçimler tamamlanmaktadır. Son olarak sayfa üzerindeki Hesapla butonuna tıklandığında EIDT programı, en uygun takma uçlu matkap, uçları ve kesme parametrelerini belirleme işlemini başlatır.

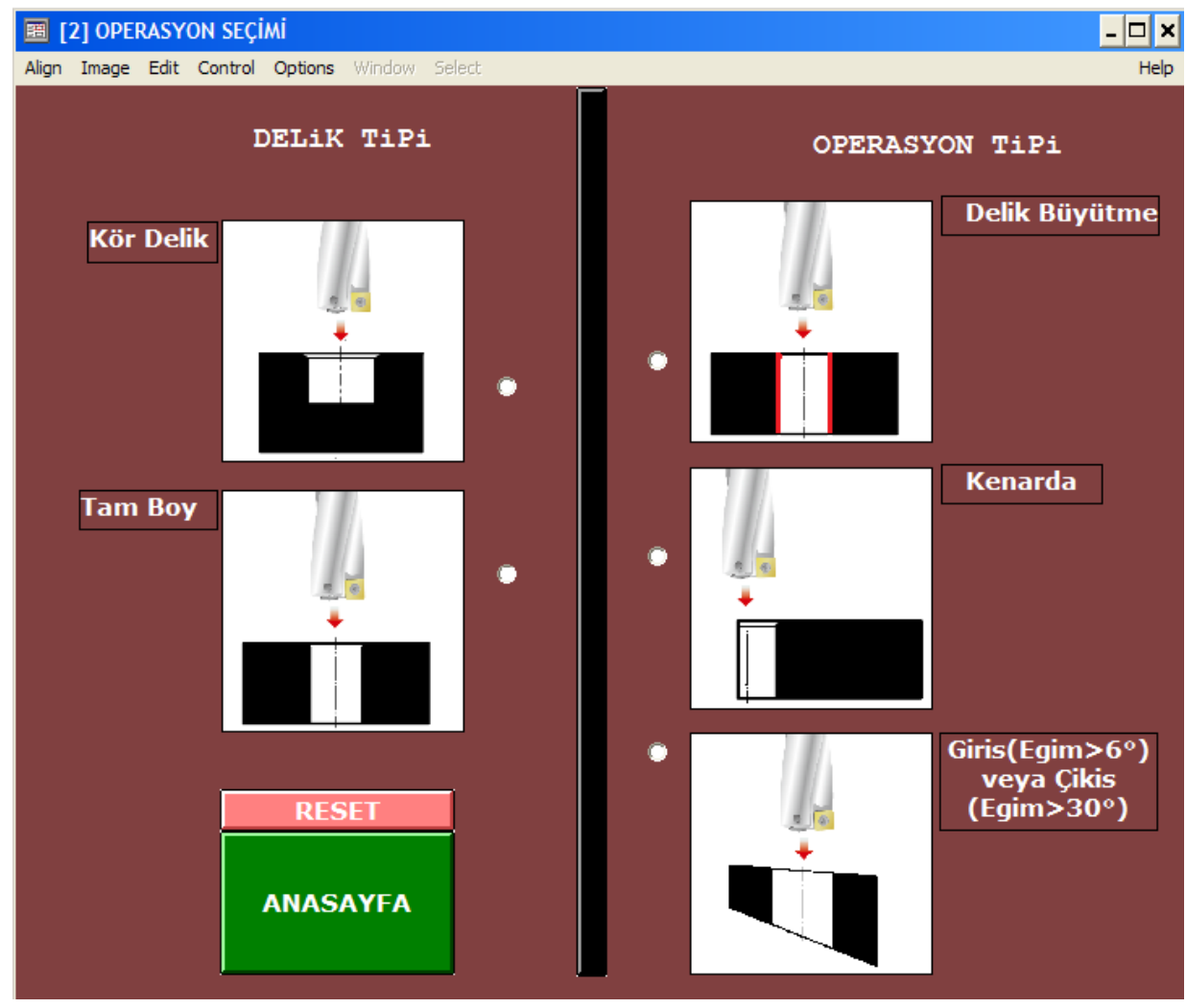

Şekil 6. Operasyon seçimi sayfasına geçiş ve operasyon ekranı

Örnek olarak EIDT programı çalıştırılıp Tablo 1'de verilen bilgiler girilmiştir. Tablo 1'de verilen bilgilerden, ilk tabloda (ANA SAYFA) olanlar programın ilk sayfasına ait olup ikinci tablodaki (OPERASYON SEÇIMI) bilgiler ise programın ikinci sayfasına aittir. Bilgi girişlerinin ardından geliştirilen uzman sistem, bulduğu önerileri Şekil 9'da verilen sayfa üzerinde kullanıcıya 
sunmaktadır. Verilen öneri sayfasında, takma uçlu matkap (UDRILL), kesici uçları (kenar ve merkez olmak üzere iki adet), uç kaplaması, kesme parametreleri (ilerleme ve kesme hızı) kullanıcıya verilmektedir. Kullanıcı isterse bu seçimi doğrudan kullanır, istemez ise program Anasayfa üzerinde bulunan Reset düğmesi ile işlemleri baştan başlatabilir.

Tablo 1. Örnek uygulama için verilen kullanıcı bilgileri

\begin{tabular}{|c|c|c|c|}
\hline & ANA SAYFA & $\overline{\text { OPERA }}$ & YYON SECİMİ \\
\hline Delik çap1 & $25 \mathrm{~mm}$ & Delik tipi & Tam Boy \\
\hline Delik boyu & $45 \mathrm{~mm}$ & \multirow{3}{*}{ Operasyon tipi } & \multirow{3}{*}{$\begin{array}{l}\text { Giriş }\left(\text { Eğim }>6^{\circ}\right) \text { veya } \\
\text { Çıkış }\left(\text { Eğim }>30^{\circ}\right)\end{array}$} \\
\hline Tolerans & H12 & & \\
\hline Malzeme & M (Ferritik ve Martenzitik Seri) & & \\
\hline
\end{tabular}

Girilen bilgilere göre Şekil 7'de önerilen sonuçlar için, program kural tabanında bulunan 150 adet kuralı değerlendirmiştir. EIDT programına, istenirse "Bu sonuca nasıl ulaştın?" sorusu sorulabilir. Bunun içinde program öneri sayfası üzerinde bulunan Açılama butonu kullanılabilir. Bilindiği gibi, Kappa-PC programı kural tabanında yazılmış olan kurallar, hiyerarşik bir yapı içerisinde birbirlerine bağlı çalışmaktadır (Şekil 8). EIDT sisteminde kuralların değerlendirilmesinde forward chaining karar verme yöntemi kullanılmaktadır. Kullanıcının girdiği bilgilere göre, kural tabanındaki en uygun kurallar dikkate alınmıştır. Şekil 7'de verilen sonuçlar için EIDT kural tabanında kullanılan kurallardan bazı örnekler Şekil 9'da'verilmiştir.

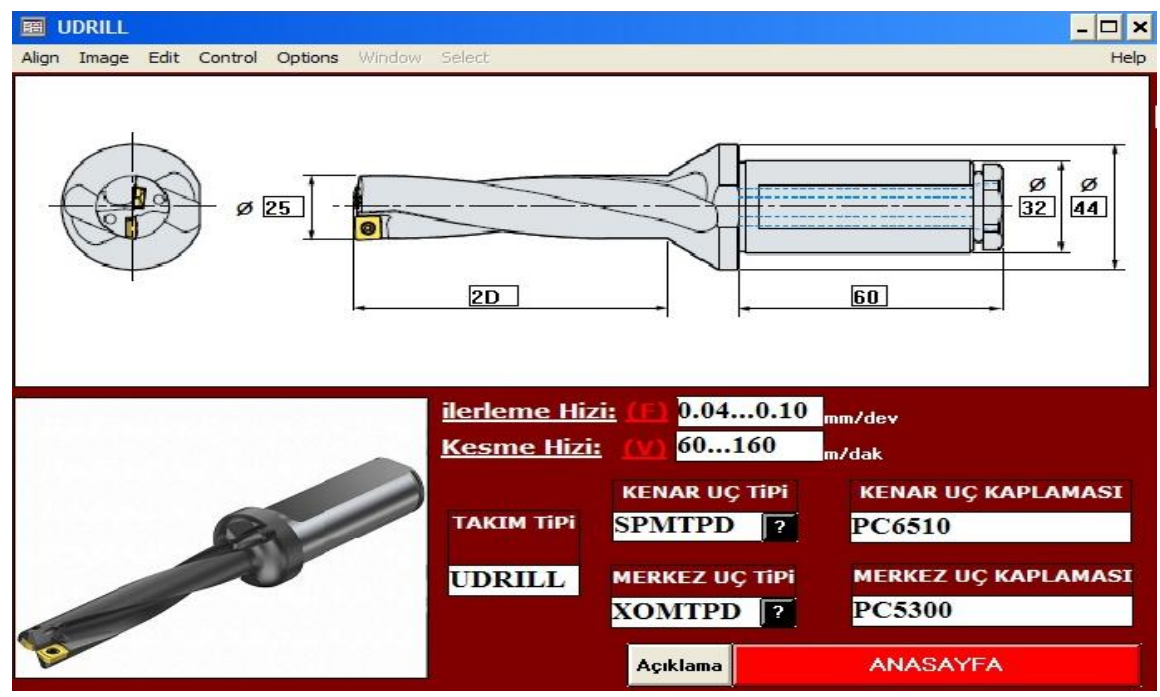

Şekil 7. EIDT uzman sistemin önerdiği takım, kesici uç ve kesme parametre çıktı ekranı 


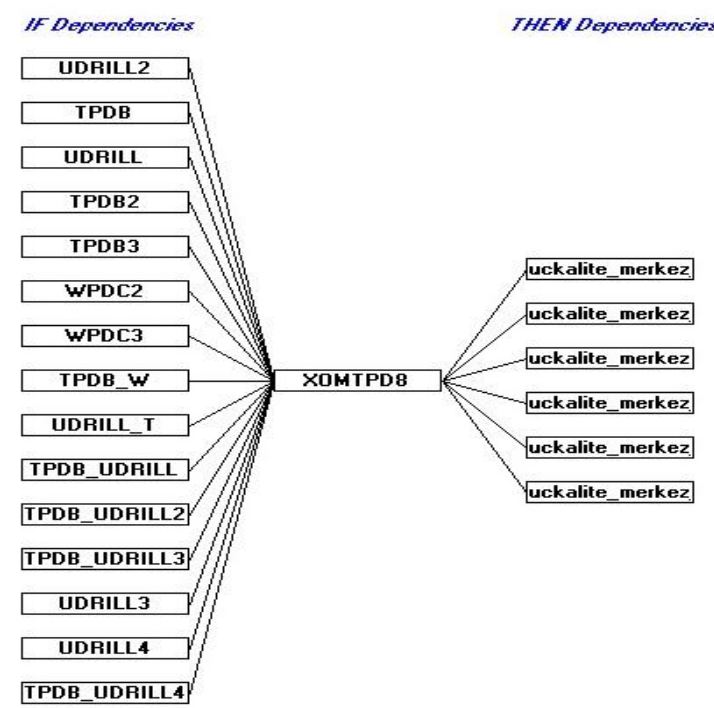

Şekil 8. Kural İlişkileri

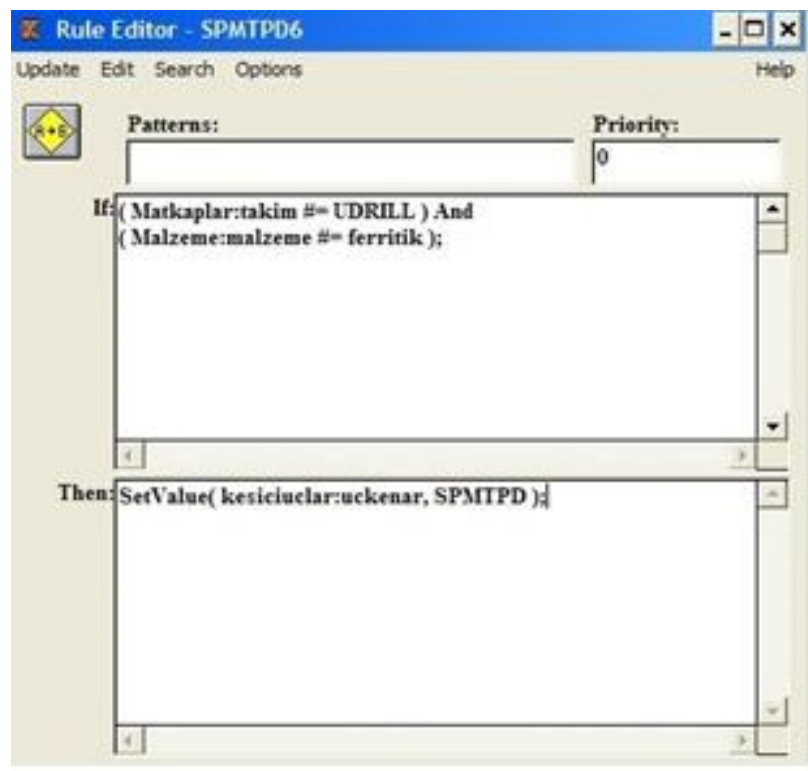

a)

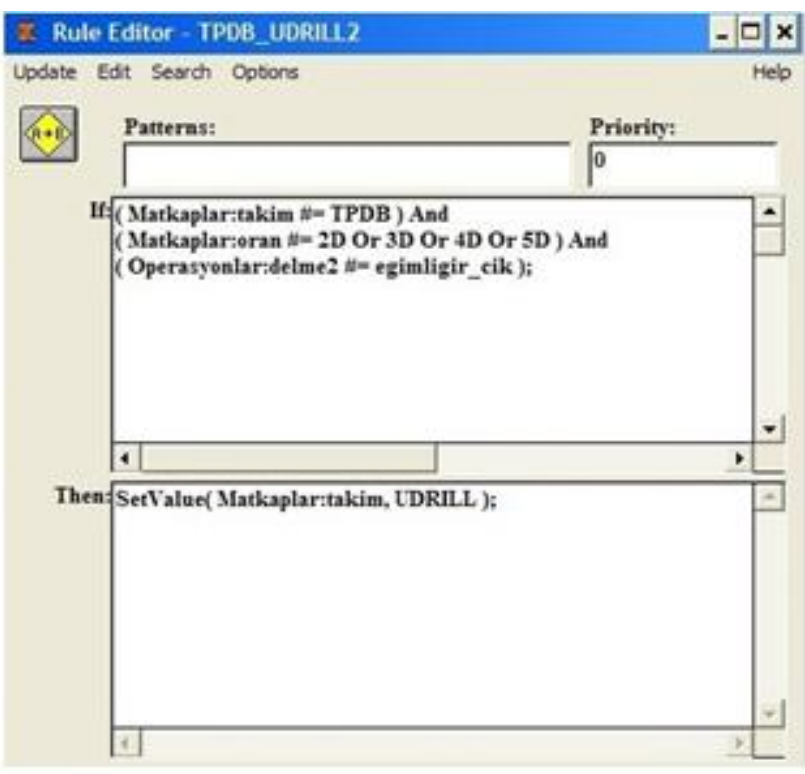

b)

Şekil 9. Kurallar a) Kenar uç profile için, b) Eğimli giriş için

\section{Sonuç}

Yapılan bu çalışmada, delik delme işlemlerinde kullanılan takma uçlu matkapların seçimine yönelik bir sistem geliştirilmiştir. Geliştirilen EIDT programı ile delik delme ve takma uçlu matkaplar konusunda uzman olmayan bir kişinin yapılacak olan bir delik delme işleminde kullanılacak en uygun takma uçlu matkabı ve kesme parametrelerini belirleyebilmesi mümkündür. Böylelikle, EIDT programı sayesinde kullanıcı, piyasada yaygın olarak kullanılan takma uçlu matkap (UDRILL, TPDB, WPDC, vb.) imalatı yapan bir kesici firmanın kataloğunu karıştırmadan, uzun zaman alacak arama-bulma faaliyetlerine girmeden ve karar verme endişesini taşımadan rahatlıkla en uygun takma uçlu matkabı seçebilmektedir. EIDT matkap seçimi programının geliştirilmesinde, piyasada yaygın olarak kullanılan takma uçlu matkaplar (UDRILL, TPDB, WPDC, vb.) için kesici imalatı yapan bir firmanın katalog verileri kullanılmıştır [25].

Geliştirilen uzman sistem, takma uçlu delik delme takımları için yapılmış olmasına rağmen farklı işleme operasyonları için kullanılan takımlar için de örnek teşkil edecektir. Böylece talaşlı imalat 
operasyonları için takım seçme sürecinde kullanıcı inisiyatifi en aza indirilerek insan kaynaklı olası hataların giderilmesi sağlanmış olunacaktır.

\section{Kaynaklar}

[1] Kayır Y., "Optimization of the Cutting Parameters for Drilling Mag. Alloy AZ91", Materials Testing, 2010, 56 (1): 47-53.

[2] Meral G., Sarıkaya M. and Dilipak H., "At the Drilling Applications Optimization of Quality of Drill via Taguchi Method”, Engineering and Machine, 2011, 52: 42-49.

[3] Saranya K., J. Jegaraj J. R., Kumar K. R., Rao G. V. "Artificial Intelligence Based Selection of Optimal Cutting Tool and Process Parameters for Effective Turning and Milling Operations", J. Inst. Eng. India Ser. C, 2016, 1-12.

[4] Bouaiachi Y., Khaldi M., Azmani A., “A Prototype Expert System for Academic Orientation and Student Major Selection", International Journal of Scientific \& Engineering Research, 2014, 5 (11):

[5] Wahidin L. S., Tan C, Khalil S. N., Juffrizal K. and Nidzamuddin M. Y. "A knowledge-based design for assemble system for vehicle seat" AIP Conference, (2015).

[6] Ayman M. A. A., "A Prototype Rule-based Expert System with an Object-Oriented Database for University Undergraduate Major Selection", International Journal of Applied Information Systems, 2012, 4(8).

[7] Nabiyev V. V. "Yapay Zeka”, Seçkin Yayınları, Ankara, (2017).

[8] Şahin İ., "Uzman sistem kullanarak 2B'lu iz düşümlerden katı Model oluşturma”, Doktora Tezi, G. Ü., Fen Bilimleri Enstitüsü, (2008).

[9] Fidan S., "Endüstri mühendisliğinde uzman sistemler ve proje yönetim yazılımı seçimine bir uzman sistem yaklaşımı", Doktora Tezi, İ.T.Ü., Fen Bilimleri Enstitüsü, (1994).

[10] Muthsam, H., Mayer, C.. "An Expert System for Process Planning of Prismatic Workpieces", 1st. International Conference on AI and Expert System Manufacturing, (1990), 211-220.

[11] Eskicioğlu, H. and Davies, B. J.. "An Interactive Process Planning System for Prismatic PartsICAP", Anenals of the CIRP, 32(1), (1983).

[12] Arezoo, B., Ridgway, K.,. "The Application of Expert Systems to the Selection of Cutting Tools and Conditions for Machining Operations", 1st. International Conference on AI and Expert System Manufacturing, 113-126, (1990).

[13] Tan C. F, Ranjit S.S.S, Kher V. K., “An Expert Carbide Cutting Tools Selection Sytem for CNC lathe Machine”, I.R.M.E. 2012, 6(7).

[14] Tan C. F., Khalil S. N., Karjanto J., Wahidin L. S., Chen W. and Rauterberg G. W. M. “An Expert Machine Tools Selection System for Turning Operation", 4th International Conference on Cooling \& Heating Technologies ICCHT, (2014).

[15] Ugraş, A., Kayır, Y., "An Expert System for Boring Tools used for Machining Holes”, ICAT 16, Konya, September 01-03, (2016).

[16] Başak, H., "Uzman sistem yaklaşımı ile vida açma operasyonları için kılavuz seçimi”, P. Ü., Mühendislik Bilimleri Dergisi, 1999, 5(1), 901-910.

[17] Kağan T., Kayır Y. "To Select Aluminium Alloys for Many Applications with an Expert System", ICAT 16, Konya, September 01-03, (2016).

[18] Zarandi M. H. F., Mansour S., Hosseinijou S. A. and Avazbeigi M., "A material selection methodology and expert system for sustainable product design”, Int J Adv Manuf Technol, 2011, 57:885-903.

[19] Usta, Y., "Robotlu bir İmalat Hücresindeki Taşıma İşlemleri için Modele Dayalı Bir Uzman Sistem Geliştirilmesi”, Gazi Üniversitesi Mühendislik Mimarlık Fakültesi Dergisi, 2005, 20(2): 275-288.

[20] Tan C. F., Khalil S. N., Nidzamuddin M. Y., Rauterberg G. V.M, “A Knowledge-Based Industrial Robot Selection System for Manufacturing Industries", I.R.M.E., 2014, 8(6).

[21] Kayır Y., Usta M., "Üniversal torna tezgâhında içten soğutmalı karbür matkaplarla aısı 1050 
malzemesinin delinmesinde kesme kuvvetleri ve sıcaklık etkisinin araştırılması", UMAS, 247256, (2017).

[22] Parsian A., Magneval M., Eyninan M., Beno T., "Time domain simulationof chatter vibration in indexable drills", Int. J. Adv. Manufacturing Technology, 2017, 89, 1209-1217.

[23] Korucu, S. Günay M, Kurt A. Şeker U, Yekpare takma uçlu matkaplarla delme işlemlerinde kesici takim üzerindeki gerilmelerin matematiksel modellenmesi, 5. Uluslararas1 İleri Teknolojiler Sempozyumu, IATS’09, Karabük, 13-15 Mayis, 1296-1304, (2009).

[24] Bayraktar, S., Siyambaş Y.,Turgut Y., "Delik delme prosesi bir araştırma”, Sakarya Üniversitesi Fen Bilimleri Enstitüsü Dergisi, 2017, 21(2): 120-130.

[25] Korloy Takım Kataloğu, Koroloy, (2017).

[26] KAPPA (version 2.3) Referans Manual, Intellicorp, Inc., USA, (1991). 